\title{
Modelling of structural flexibility of the railway vehicles carbody
}

\author{
Mădălina Dumitriu* and Camil Crăciun \\ University Politehnica of Bucharest, Department of Railway Vehicles, 313 Splaiul Independenţei, \\ 060042, Bucharest, Romania
}

\begin{abstract}
The accuracy in the models of railway vehicles in the ride comfort evaluation mainly derives from the modelling of the carbody structural flexibility. The former part of the paper herein reviews the 'flexible carbody' type methods used to represent the carbody structural flexibility in the approaches targeting the identification of certain methods to reduce the flexible vibrations in the carbody so as to improve the ride comfort of the railway vehicles. What seems to apply are the simple beam models such as Euler - Bernoulli or Timoshenko, structure type models and detailed multi-body, finite-element models or combinations of multi-body and finite-elements models. The latter part will feature a contrastive analysis regarding the comfort index coming from the numerical simulations based on 'rigid carbody' and 'flexible carbody' original models. It is highlighted that the comfort performance of a railway vehicle evaluated on the basis of a 'rigid carbody' mode is overrated.
\end{abstract}

\section{Introduction}

While running, the railway vehicle is subjected to steady-state vibration, mainly from the track irregularities, which they are transmitted from via the bogies and the carbody to the passengers. The carbody vibration exhibits simple vibration modes - rigid modes, and complex vibration modes - vibration due to the carbody structural flexibility. In some cases, this carbody structural flexibility accounts for half of the perceived vibrations, the rest being due to rigid modes [1].

Given the fact that the reduction in the weight of the railway vehicles stands as one of the most influential designing criteria, called for by the increase in velocities, need for lower energy consumption, manufacturing costs and maximization of the use of loads on the axle, the issue of the carbody structural flexibility is extremely relevant. A lower structural stiffness usually triggers a smaller weight in the carbody. The lighter the carbody, the higher its flexibility, which leads to an easier excitation of the carbody structural vibrations. The structural vibration causes carbody fatigue which affects the dynamic performance and service life of the vehicle $[2,3]$. But the most important effect of the carbody structural vibrations is visible in the ride comfort of the railway vehicles [4 - 6]. This action occurs due to the first flexible vibration modes of the carbody whose

\footnotetext{
*Corresponding author: madalinadumitriu@yahoo.com
} 
eigenfrequencies are found within the frequency interval where the human body shows a higher sensitivity to vibrations. More exactly, it is about the first mode of carbody vertical bending with the frequency usually between 6 and $12 \mathrm{~Hz}$ that has the highest influence on the ride comfort.

In the last years, numerous theoretical studies have been conducted in order to identify certain methods of reducing the ride comfort-relevant flexible vibrations of the carbody. The analytical evaluation of the comfort performance in the railway vehicles involves the use of the numerical simulation applications as an investigation instrument that are developed on the basis of certain theoretical models of the vehicle [7]. The precision of the models largely depends on the carbody modelling. The 'rigid carbody' simple model can be used to explain some basic phenomena of the vibration behaviour in the railway vehicle. This model, however, becomes unsuitable when the ride comfort is being evaluated, as will seen in this paper. The results derived from such models prove that the critical positions in terms of ride comfort are found at the ends of the carbody. This fact does not always reflect in reality, since there are situations in which the level of vibrations at the carbody centre is comparable with the level recorded at its ends $[4,8]$.

The former part of the paper herein reviews the models used to represent the carbody structural flexibility in the approaches targeting the identification of certain methods to reduce the flexible vibrations in the carbody so as to improve the ride comfort of the railway vehicles. The latter part will include an evaluation of the ride comfort in high speed trains, by using the results from numerical simulations based on both 'rigid carbody' and 'flexible carbody' original models. These have been developed by the authors starting from the basic models by improving the secondary suspension model which includes pitch and longitudinal elements. It is therefore highlighted that the comfort performance of a railway vehicle evaluated on the basis of a 'rigid carbody' mode is overrated.

\section{Models of 'flexible carbody' type}

The models of 'flexible carbody' type vary from relatively simple Euler-Bernoulli or Timoshenko beams, to a structure type models consisting of plates and beams or multibody, finite-element detailed models or combinations between multi-body and finiteelement models.

A model widely utilized to analyze the flexible vibrations in the carbody bending or their influence upon the ride comfort consists in a free-free equivalent beam, of EulerBernoulli type. Such a model was used by Zhou et al. [5] to investigate the influences of the carbody vertical flexibility on the ride quality in the passenger railway vehicles. Dumitriu [8] studied the position of the carbody critical point in terms of the ride comfort. Tomioka and Takigami [9] employed the model of Euler-Bernoulli elastic beam for presenting a theory based on the use of the longitudinal vibration in bogies as a dynamic vibration absorber (DVA) to reduce the vertical bending vibration of railway vehicle carbodies. In a study on the dynamic analysis of the influence of carbody flexibility upon the dynamic response of the train-bridge system, Kunpeng et al. [10] established a three-dimensional (3D) model of the vehicle based on flexible multi-body dynamics, where the carbody is simulated as an Euler-Bernoulli beam.

The same beam model is adopted to represent the carbody in more papers, in order to examine the influence of the equipment suspended from the carbody chassis upon the vibration of the flexible carbody for high-speed electric multiple unit (EMU). For instance, Dumitriu [11] evaluated the influence of the suspended equipment and of its fastening manner (rigid or elastic), in correlation with the speed behaviour upon the regime of vertical vibrations in the carbody at the high speed trains. Shi et al. [12] applied the theory of dynamic vibration absorber (DVA) to restrain the vibration of carbody for high-speed 
electric multiple unit. For this purpose, the carbody was modelled as an Euler-Bernoulli beam with the equipment mounted on the chassis regarded as a DVA. Relying on this model, the influence of the suspension parameters of equipment on the flexible vibration reduction of carbody is studied, while including the suspension frequency, damping ratio, mounting position, and mass of equipment.

The use of the Euler-Bernoulli beam is also suitable for the elaboration of certain methods to reduce the flexible vibrations in the carbody of the railway vehicles, based on the piezoelectric elements in passive control and active control systems. Hansson et al. [13], for example, modelled the vehicle carbody as an elastically supported Bernoulli-Euler beam in their study for a method to improve the riding comfort by reducing vertical flexural vibrations in railway carbodies via piezoelectric elements. These elements are attached on the carbody to convert the vibration energy into electrical energy, which can be dissipated in a shunt circuit. Kamada et al. [14] submitted a method for the active control of the vibrations in the carbody of the railway vehicles based on the combined use of the piezoelectric actuators and linear actuators. Thus, elastic vibrations are suppressed by piezoelectric actuators and rigid-body vibrations are reduced by linear actuators.

The theory of Timoshenko beam is frequently applied for the track modelling [15] and more rarely for the same action on the vehicle carbody. The carbody is modelled via a Timoshenko beam when taking into account both bending deformation and also shear deformation. Yang et al. [2] applied a method based on Timoshenko beam theory to infer an analytical formula for the calculation of the first frequency of the carbody vertical bending. To study the vertical vibrations of a vehicle running on a track with irregularities, Young and Li [16] modelled the carbody as a Timoshenko beam with limited length. With the help of a numerical procedure to simulate the vibrations in the vehicle, the effect of the carbody flexibility upon the vertical vibrations in the vehicle/track system is investigated.

The analysis of the 3D flexible carbody vibrations of the railway vehicles uses structure type models, multibody models (MBMs), finite element models (FEMs) or MBM with the FEM combinations. Tomioka et al. [17] proposed an analytical method to investigate the 3D flexural vibration of railway vehicle carbodies in which the carbody is modelled as a box-type structure consisting of plates and beams. To investigate the improvement in the ride comfort of lightweight railway vehicles by means of an active vibration reduction system using piezo-stack actuators, Schandl et al. [6] used a MBM of the vehicle. Diana et al. [4] developed a complex FEM of the vehicle, suitable for reproducing its dynamic behaviour in the $0 \ldots 50 \mathrm{~Hz}$ frequency range, especially with respect to the ride comfort problem. Carlbom [1] combined the multibody system theory with the FE method so as to examine the dynamic response of the railway vehicle.

\section{Evaluation of the ride comfort}

This section features the evaluation of the ride comfort at the vertical vibrations for a railway vehicle, based on the partial comfort index $\left(N_{M V}\right)$ obtained from numerical simulations. To this end, the vehicle is represented by both a 'rigid carbody' and also a 'flexible carbody' type models (see Fig. 1). The vehicle is running on a perfectly rigid track with vertical irregularities that are described against each axle by the functions $\eta_{1 \ldots . .4}$. The track vertical irregularities are considered to represent a stationary stochastic process that can be described by means of the power spectral density [18].

In the 'rigid carbody' model, the carbody is described by a rigid body with two vibration modes, i.e. bounce $z_{c}$ and pitch $\theta_{c}$. For the 'flexible carbody' type, the carbody is represented by a free-free equivalent beam, a constant section and uniformly distributed mass, of Euler-Bernoulli type. 

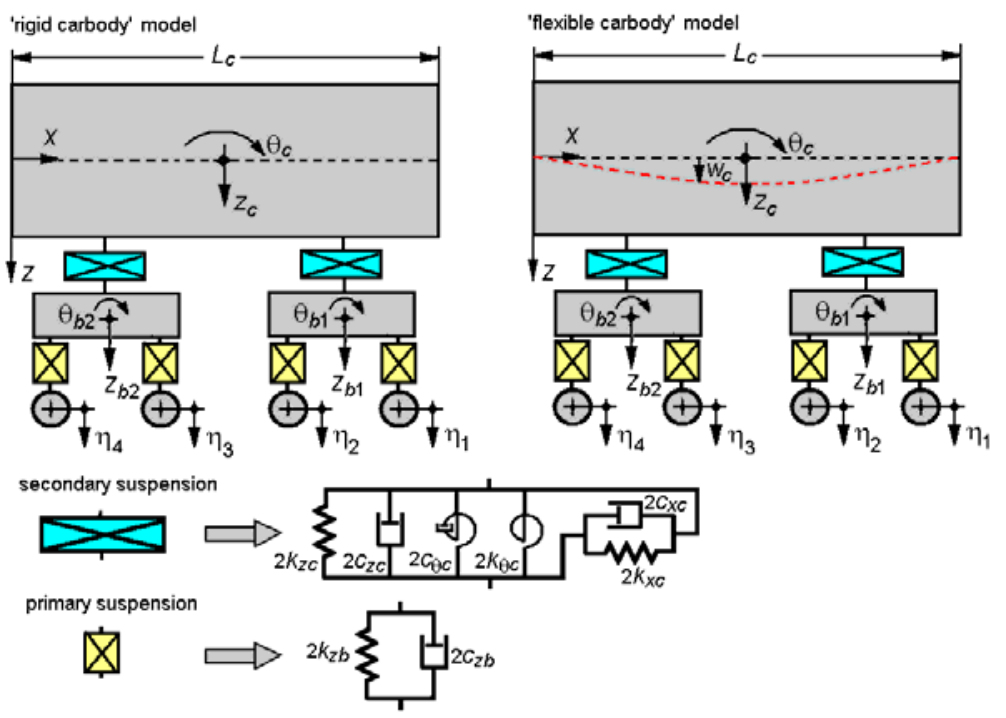

Fig. 1. The vehicle model: 'rigid carbody' model; , flexible carbody' model.

The carbody displacement $w_{c}(x, t)$ is the result of overlapping between the rigid modes of vibration - bounce $z_{c}$ and pitch $\theta_{c}$ and the first mode of carbody structural vibration vertical bending,

$$
w_{c}(x, t)=z_{c}(t)+\left(x-L_{c} / 2\right) \theta_{c}(t)+X_{c}(x) T_{c}(t),
$$

where $L_{c}$ is the carbody length, $T_{c}(t)$ is the coordinate of the carbody vertical bending and $X_{c}(x)$ represents the natural function of this vibration mode, described in the equation

$$
X_{c}(x)=\sin \beta_{c} x+\sinh \beta_{c} x-\frac{\sin \beta_{c} L_{c}-\sinh \beta_{c} L_{c}}{\cos \beta_{c} L_{c}-\cosh \beta_{c} L_{c}}\left(\cos \beta_{c} x+\cosh \beta_{c} x\right)
$$

with

$$
\beta_{c}=\sqrt[4]{\omega_{c}^{2} \rho_{c} /(E I)}, \cos \beta_{c} L_{c} \cosh \beta_{c} L_{c}-1=0,
$$

where $\omega_{c}$ is the natural pulsation of the carbody bending.

For both models, each bogie is represented by a rigid body which is able to perform two motions in a vertical plan, namely bounce $z_{b i}$ and pitch $\theta_{b i}$, with $i=1,2$.

The model of the secondary suspension to a bogie includes two Kelvin-Voigt systems; one of them is for vertical translation, with stiffness $2 k_{z c}$ and damping constant $2 c_{z c}$, and another one for rotation, with the pitch angular stiffness $2 k_{\theta_{c}}$ and damping constant $2 c \theta_{c}$. The model of the secondary suspension also includes a Kelvin-Voigt system which models the transmission system of the longitudinal forces between the carbody and bogie. This model has an elastic constant $2 k_{x c}$ and a damping constant $2 c_{x c}$. The primary suspension corresponding to an axle is modelled via a Kelvin-Voigt system, with the elastic constant $2 k_{z b}$ and the damping constant $2 c_{z b}$.

The motion relations of the carbody and bogies come from the implementation of the laws of mechanics. While the 'rigid carbody' model has six motion equations with ordinary derivatives, the 'flexible carbody' acquires four such equations - the motion equations of the bogies and the carbody, written as below

$$
E I \frac{\partial^{4} w_{c}(x, t)}{\partial x^{4}}+\mu I \frac{\partial^{5} w_{c}(x, t)}{\partial x^{4} \partial t}+\rho_{c} \frac{\partial^{2} w_{c}(x, t)}{\partial t^{2}}=\sum_{i=1}^{2} F_{z c i} \delta\left(x-l_{i}\right)+\sum_{i=1}^{2}\left(M_{c i}-h_{c} F_{x c i}\right) \frac{\mathrm{d} \delta\left(x-l_{i}\right)}{\mathrm{d} x},
$$


where $\delta($.$) is Dirac's delta function and F_{z c i}, F_{x c i}$ and $M_{i}$ stand for the forces and moments due to the secondary suspension of bogie $i$. To solve this equation, the modal analysis method is applied, well known in vibration theory [19]. The answer will be three motion equations, corresponding to the vibration modes of the carbody.

Table 1. The parameters of the vehicle numerical model.

\begin{tabular}{|l|l|l|l|}
\hline$m_{c}=34.0 \cdot 10^{3} \mathrm{~kg}$ & $E I=3.16 \cdot 10^{9} \mathrm{Nm}^{2}$ & $2 k_{z c}=1.20 \mathrm{MN} / \mathrm{m}$ & $2 c_{x c}=50.0 \mathrm{kNs} / \mathrm{m}$ \\
\hline$m_{b}=3.20 \cdot 10^{3} \mathrm{~kg}$ & $L=26.4 \mathrm{~m}$ & $2 k_{x c}=4.00 \mathrm{MN} / \mathrm{m}$ & $2 c_{\theta c}=2.00 \mathrm{kNm}$ \\
\hline$m_{m c}=35.2 \cdot 10^{3} \mathrm{~kg}$ & $2 a_{c}=19.0 \mathrm{~m} ; 2 a_{b}=2.56 \mathrm{~m}$ & $2 k_{\theta \mathrm{c}}=256 \mathrm{kN} / \mathrm{m}$ & $2 c_{z c}=34.3 \mathrm{kNs} / \mathrm{m}$ \\
\hline$J_{c}=1.96 \cdot 10^{6} \mathrm{~kg} \cdot \mathrm{m}^{2}$ & $h_{c}=1.30 \mathrm{~m}$ & $4 k_{z b}=4.40 \mathrm{MN} / \mathrm{m}$ & $4 c_{z b}=52.2 \mathrm{kNs} / \mathrm{m}$ \\
\hline$J_{b}=2.05 \cdot 10^{3} \mathrm{~kg} \cdot \mathrm{m}^{2}$ & $h_{b}=0.20 \mathrm{~m}$ & $k_{m c}=89.0 \mathrm{MN} / \mathrm{m}$ & $c_{m c}=53.1 \mathrm{kNm} / \mathrm{s}$ \\
\hline
\end{tabular}

Table 3. The natural frequencies of the vehicle vibration modes.

\begin{tabular}{|l|c|l|c|}
\hline Carbody vibration mode & Frequency & Bogie vibration mode & Frequency \\
\hline Carbody bounce & $1.17 \mathrm{~Hz}$ & Bogie bounce & $6.61 \mathrm{~Hz}$ \\
\hline Carbody pitch & $1.46 \mathrm{~Hz}$ & Bogie pitch & $9.63 \mathrm{~Hz}$ \\
\hline Carbody bending & $8.00 \mathrm{~Hz}$ & & \\
\hline
\end{tabular}

The results of the numerical simulations derived from the models above are featured in Fig. 2 and 3. The same parameters of numerical simulation have been considered, where their selection is congruent with a high speed train (Table 1). The natural frequencies of the vibration modes in the carbody and bogie are featured in Table 2.
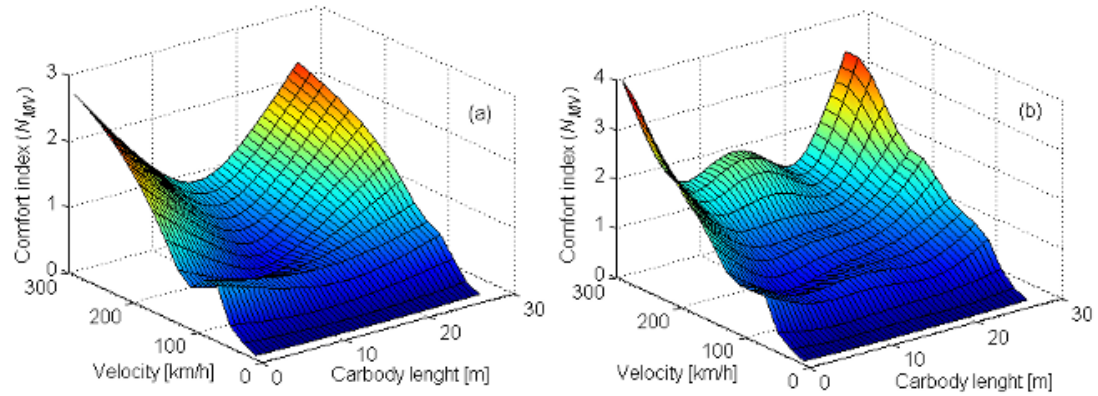

Fig. 2. Comfort index: (a) 'rigid carbody' model; (b) ‘flexible carbody' model.

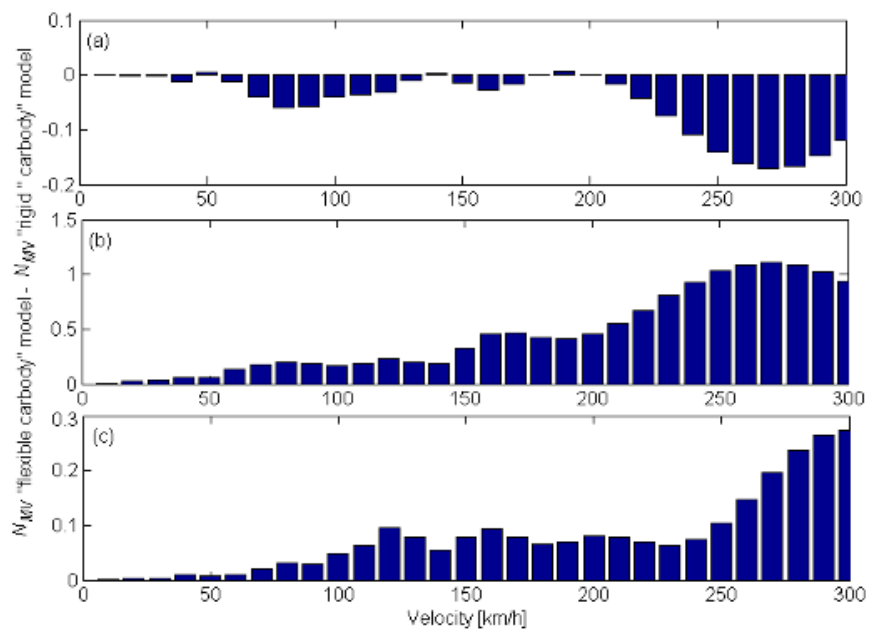

Fig. 3. $N_{M V}$ 'flexible carbody' model - $N_{M V}$ 'rigid carbody' model: (a) above the front bogie; (b) at the carbody centre; (c) above the rear bogie. 
Fig. 2 shows the $N_{M V}$ calculated along the carbody, in dependence on the velocity, according the standard for evaluation of ride comfort for rail passengers [20]. Differences between the results coming from the two models are noticed and they become more obvious along with the speed increase. As a rule, it is about an overestimation of the ride comfort evaluated by means of the ,rigid carbody' model. The same thing is pointed out at in the diagrams in Fig. 3, displaying the difference between $N_{M V}$ calculated on the basis of 'flexible carbody' model and 'rigid carbody' model at the carbody centre and against the bogies. The highest difference between these results occur at the carbody centre, where the level of vibrations increases with the velocity, due to the vertical bending of the carbody. These results are consistent with the ones derived from other research [4].

\section{Conclusions}

The representation of the carbody flexibility is still an essential element for the accuracy of the railway vehicle model which is used in the studies targeting the identification of certain methods to reduce the carbody vibrations and improve the ride comfort. The part one in this paper reviewed the 'flexible carbody' models used in such studies and the part two evaluated the ride comfort for a high speed train, based on the comfort index from numerical simulations. The results from 'flexible carbody' and 'rigid carbody' models are compared and an overestimation in the comfort performance is demonstrated with the latter model. The differences are quite visible mainly at the carbody centre, where the level of vibrations increases with the velocity, due to the vertical carbody bending.

This work has been funded by University Politehnica of Bucharest, through the "Excellence Research Grants" Program, UPB - GEX - 2016. Research project title: Research on developing mechanical and numerical models for the virtual evaluation of the dynamic performances in the railway vehicles (in Romanian). Contract number: 48/26.09.2016.

\section{References}

1. P. Carlbom, Carbody in rail vehicle dynamics (Ph.D Thesis, Stockholm, 2000)

2. G. Yang, C. Wang, F. Xiang, S. Xiao, Chinese J. Mech.1 Eng. 29, 6, 1120-1126 (2016)

3. C. Hui, Z. Weihua, M. Bingrong, Int. J. Veh. Struct. Syst. 7, 2, 55-60 (2015)

4. G. Diana, F. Cheli, A. Collina, R. et al., Veh. Syst. Dyn 38, 3, 165-185 (2002)

5. J. Zhou, R. Goodall, L. Ren, H. Zhang, Proc. IMechE, Part F 223, 461-471 (2009)

6. G. Schandl, P. Lugner, C. Benatzky, et al., Veh. Syst. Dyn. 45, 9, 835-847 (2007)

7. G. Schupp, Mech. Based Des. Struct. Mach. 31, 3, 297-314 (2003)

8. M. Dumitriu, Archive of Mechanical Engineering 61, 4, 609-625 (2014)

9. T. Tomioka, T. Takigami, Veh. Syst. Dyn. 48, Suppl., 467-486 (2010)

10. W. Kunpeng, X. He, X. Man, J. Mech. Sci. Tech. 29, 9, 3571-3580 (2015)

11. M. Dumitriu, Archive of Mechanical Engineering 63, 1, 25-44 (2016)

12. H. Shi, R. Luo, P. Wu, J. Zeng, J. Guo, Sci. China Tech. Sci. 57, 7, 1425-1438 (2014)

13. J. Hansson, M. Takano, T. Takigami, et al., JSME Int. J., Ser. C 47, 2, 451-456 (2004)

14. T. Kamada, T. Hiraizumi, M. Nagai, Veh. Syst. Dyn. 48, 73-87 (2010)

15. T. Mazilu, Veh. Syst. Dyn. 48, 9, 1021-1042 (2010)

16. T.H. Young, C.Y. Li, Veh.Syst.Dyn. 40, 5, 329-349 (2003)

17. T. Tomioka, T. Takigami, Y. Suzuki, Veh. Syst. Dyn. 44, Suppl., 272-285 (2006)

18. ORE C 116/RP1, Interaction between vehicles and track (Utrecht, 1971)

19. A.A. Shabana, Theory of vibration (Springer-Verlag, 1991)

20. ENV 12299, Railway applications ride comfort for passengers measurement and evaluation (1997) 